\title{
Trophic behaviour of the dragonfly Cordulegaster boltoni (Insecta: Odonata) in small creeks in NW Italy
}

\author{
Tiziano Bo, Stefano Fenoglio*, Manuel Jesus López-Rodríguez \\ \& José Manuel Tierno de Figueroa
}

\begin{abstract}
Bo, T., Fenoglio*, S., López-Rodríguez, M. J. \& Tierno de Figueroa, J. M. 2011: Trophic behaviour of the dragonfly Cordulegaster boltoni (Insecta: Odonata) in small creeks in NW Italy. — Entomol. Fennica 22: 255-261.
\end{abstract}

The order Odonata comprises many predaceous species that inhabit aquatic systems, and a few that are restricted to flowing waters. Cordulegaster boltoni is a widespread Odonata in Europe, which usually inhabits small lotic systems. In this study we analysed the gut contents of $C$. boltoni immature stages, collected in the Rocchetta Tanaro Natural Park (Italy, Piemonte). Two hundred and eleven individuals were collected, and their diet analyzed by dissection or clearing. Larvae appeared to be opportunistic predators, feeding on a variety of prey. Aquatic insects dominated their diet, while crustaceans, annelids, molluscs and terrestrial invertebrates were sporadically observed in the gut contents. An ontogenetic shift in the diet was detected, as small larvae consumed different prey than large ones. Our study suggests that $C$. boltoni is one of the dominant predators in the benthic communities of lowland small order streams of Piemonte, which, because of their environmental characteristics, are devoid of fish and stoneflies.

T. Bo \& S. Fenoglio (*corresponding author), Dipartimento di Scienze dell'Ambiente e della Vita, Università del Piemonte Orientale, Via Tersa Michel 11, 15121, Alessandria, Italy. Corresponding author's e-mail: stefano.fenoglio (a)mfn.unipmn.it

M. J. López-Rodríguez, Departamento de Ecología, Facultad de Ciencias, Universidad de Granada, 18071, Granada, Spain

J. M. Tierno de Figueroa, Departamento de Zoology, Facultad de Ciencias, Universidad de Granada, 18071 Granada, Spain

Received 7 March 2011, accepted 8 July 2011

\section{Introduction}

Aquatic insects have an important role in the trophic structure of lotic systems, and the number of studies focused on their feeding habits has been increasing (e.g. Monakov 2003, Bo et al. 2008, López-Rodríguez et al. 2009). Odonata inhabit a broad range of habitats, including ponds, lakes, swamps, marshes and streams. Few families, such as Calopterygidae, Cordulegasteridae, and, to a lesser extent, Gomphidae, are restricted to flowing waters.

Despite their important trophic role, relatively few studies investigated feeding habits of Odonata, particularly in flowing water ecosystems. Odonata are predatory insects, both in the adult and nymphal stages. In particular, Odonata immatures are generally ambush predators that 
detect prey using mechanical and visual stimuli. Rebora et al. (2004) tested the response of Anisoptera larvae to different kind of prey stimuli, and observed that chemical cues seem to have little or no contribution in the detection of prey. Blois (1990) investigated prey preferences of Anax imperator Leach, 1815 in an experimental study with two prey types (Chironomidae and Corixidae), and detected that larvae of this species generally feed on the most abundant prey. A recent study, conducted on large species such as Anax imperator, Aeshna cyanea (Müller, 1764) and Libellula depressa Linnaeus, 1758, concluded that larval diets changed with developmental stage (Blois 2006), with an increase of size and diversity of prey items correlated to increasing size of larvae. In the same study, prey preferences and selection mechanisms in these three species were observed. The trophic preferences of nymphs of Enallagma Charpentier, 1840 (Coenagrionidae) have been investigated in laboratory enclosures with different habitat complexity and using selected prey types. The results from this study indicate that prey vulnerability to Enallagma predation is species-specific rather than habitat-determined (Lombardo 1997). These and other studies are focused mainly on lentic species of Odonata, and mostly analysed feeding behaviour in laboratory assays (Bergelson 1985, Blois 1985, Blois \& Cloarec 1985, Johnson 1991, Rebora et al. 2004).

The family Cordulegasteridae is represented in Europe by the sole genus Cordulegaster Leach, 1815 (Lohmann 1992, 1993), which has a Holarctic distribution (Askew 2004). Three species are present in Italy: Cordulegaster bidentata Sélys, 1843, C. boltoni (Donovan, 1807), and $C$. picta Sélys, 1854. Cordulegaster trinacriae Waterston, 1976, known from Sicily and mainland Italy, can be considered a subspecies of either $C$. boltoni or, according to other authors, C. picta (Askew 2004). Cordulegaster boltoni, commonly named Golden-ringed Dragonfly, occurs in Europe from southern Spain and Italy to southern Scandinavia, and is also reported from Tunisia, Algeria and Morocco (Askew 2004). This species inhabits small lotic systems, where larvae construct shallow depressions in fine sediments. Cordulegaster boltoni is a partivoltine taxon (Corbet et al. 1960, Corbet 1962), with a pro- longed and relatively flexible pre-imaginal development. Different lengths of larval life has been observed in different areas: three or two years in southern Spain (Ferreras-Romero \& Corbet 1999) and Mediterranean France (Schütte 1997), four to five years in northeastern Germany (Donath 1987) and Yugoslavia (Kiauta 1964), and more than five years in the United Kingdom (Corbet et al. 1960).

The aim of our study was to characterise the diet of immature stages of a strictly lotic dragonfly, C. boltoni, in natural conditions. Furthermore, we tested whether shifts in prey selection occurred during larval ontogenesis.

\section{Material and methods}

The study sites are located in the Rocchetta Tanaro Natural Park, northwestern Italy (4451' $35^{\prime \prime} \mathrm{N}, 8^{\circ} 20^{\prime} 48^{\prime \prime} \mathrm{E}, 130 \mathrm{~m}$ a.s.1.). The landcover is composed largely of dense woodlands with a few, little villages. The environmental quality of lotic systems of the area is good (Bo et al. 2010). The study sites are classified as first class in the Extended Biotic Index system (Ghetti 1997), which corresponds to an environment with minimal human-induced impacts.

Two small creeks, Rio Rabengo and Rio Ronsinaggio, were sampled (four stations in each lotic system). The two creeks are very close (about $1.5 \mathrm{~km}$ ) and have identical environmental characteristics. Rio Rabengo and Rio Ronsinaggio are $2^{\text {nd }}$ order perennial lotic environments, characterized by gentle slope, low to moderate water current (ranging from 10 to $20 \mathrm{~cm} / \mathrm{s}$ on average), fine substrata $(80 \%$ sand $-20 \%$ fine gravel), and high amounts of coarse vegetal detritus. The mean water depth and width were 16.4 $\mathrm{cm}( \pm 7.6 S D)$ and $91.8 \mathrm{~cm}( \pm 16.8 S D)$, respectively. Riparian vegetation is mainly composed of Alnus glutinosa, Corylus avellana, Salix alba, Populus alba, and Acer campestre. The vegetation is very dense and causes significant shading of the stream channels.

Every month from April 2008 to May 2009, macroinvertebrates were collected using a kicknet $(250 \mu \mathrm{m}$ mesh $)$, and specimens were preserved in $90 \%$ ethanol. All organisms were counted and identified to the genus level, except 
Fig. 1. A graph showing no clear grouping between two creeks, based on results of Multidimensional Scaling analysis of ingested prey items of Cordulegaster boltoni individual nymphs.

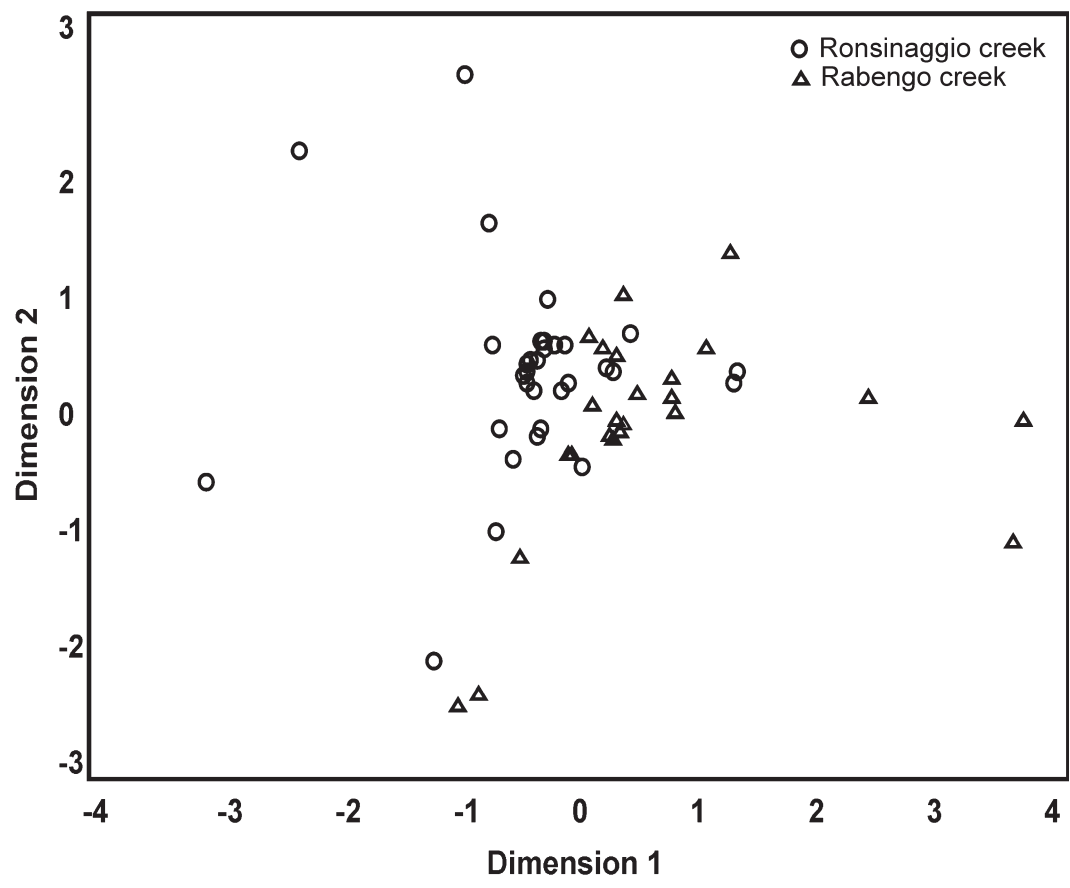

for a few groups, such as Oligochaeta and early instars of some Diptera and Trichoptera, which were identified to the family level.

The nymphs of $C$. boltoni were measured using a micrometer before their gut contents were analysed. Total length, pronotum width and right fore-wing pad length were measured $(0.1 \mathrm{~mm}$ accuracy). Two different methods were used to analyse gut contents, depending on the size of the nymphs (as in López-Rodríguez et al. 2009). Larger nymphs were dissected, while smaller larvae were chemically cleared. Dissections were performed in the ventral right side of the thorax to remove the foregut. Gut contents were spread on a Petri dish and prey identified and counted. The quantity of other food items (detritus, hyphae, coarse particulate organic matter, mineral matter and animal matter) was recorded. For smaller nymphs, the method proposed by Bello and Cabrera (1999) was used to render individuals transparent, as previously done by our team in other macroinvertebrate feeding studies (Tierno de Figueroa et al. 2003, Cammarata et al. 2007, Fenoglio et al. 2008, López-Rodríguez et al. 2009). Each individual was placed in a vial with Hertwigs' liquid and heated in an oven at $65^{\circ} \mathrm{C}$ for approximately 120 hours. The specimens were then mounted on slides for microscope analysis. Prey items were identified and counted from complete individuals or from sclerotized body parts, such as head capsules, mouthparts and legs. The count of sclerotized fragments can give a reasonably accurate estimate of prey consumed, as demonstrated for other macroinvertebrates (Stewart \& Stark 2002). Individuals that did not contain any invertebrate prey were analysed with a compound microscope equipped with an ocular micrometer to identify non-animal gut contents. The absolute percentage of gut content (at $40 \times$ as percentage of total area occupied by the contents in the whole digestive tract) and the relative abundances of each food item (at $400 \times$ as percentage of area occupied by each component of the total gut contents) were recorded.

Statistica 8.0 was used for statistical analyses (StatSoft Inc. 2008). Normality of the data was assessed by means of the Kolmogorov-Smirnov test. Variables did not follow a normal distribution, so non-parametric tests were used. Correlations between total length, pronotum width and right fore-wing pad length, as well as the correlation between size and number of prey items, were calculated using a Kendall Tau test. A Gamma correlation test (Siegel \& Castellan 1988) was 
Table 1. Gut content of Cordulegaster boltoni nymphs (Mean, Min and Max of the number of the prey item in the gut, $N=110$ guts in all cases; No. = number of guts that contained the item).

\begin{tabular}{lrrrrrr}
\hline Prey item & Mean & Min & Max & $S D$ & No. & $\%$ presence \\
\hline Ephemeroptera undet. & 0.05 & 0 & 1 & 0.23 & 6 & 0.05 \\
Baetidae & 0.01 & 0 & 1 & 0.10 & 1 & 0.01 \\
Paraleptophlebia sp. & 0.01 & 0 & 1 & 0.10 & 1 & 0.01 \\
Ecdyonurus sp. & 0.05 & 0 & 1 & 0.23 & 6 & 0.05 \\
Plecoptera undet. & 0.05 & 0 & 1 & 0.21 & 5 & 0.05 \\
Nemoura sp. & 0.02 & 0 & 1 & 0.13 & 2 & 0.02 \\
Odonata undet. & 0.01 & 0 & 1 & 0.10 & 1 & 0.01 \\
Cordulegaster sp. & 0.01 & 0 & 1 & 0.10 & 1 & 0.01 \\
Calopteryx sp. & 0.02 & 0 & 1 & 0.13 & 2 & 0.02 \\
Trichoptera undet. & 0.05 & 0 & 1 & 0.23 & 7 & 0.06 \\
Hydropsychidae & 0.04 & 0 & 3 & 0.30 & 2 & 0.02 \\
Polycentropodidae & 0.02 & 0 & 2 & 0.19 & 1 & 0.01 \\
Coleoptera undet. & 0.01 & 0 & 1 & 0.10 & 1 & 0.01 \\
Elmidae & 0.01 & 0 & 1 & 0.10 & 1 & 0.01 \\
Diptera undet. & 0.01 & 0 & 1 & 0.10 & 1 & 0.01 \\
Chironomidae & 0.35 & 0 & 3 & 0.66 & 30 & 0.27 \\
Tanypodinae & 0.01 & 0 & 1 & 0.10 & 1 & 0.01 \\
Stratiomyidae & 0.01 & 0 & 1 & 0.10 & 1 & 0.01 \\
Simuliidae & 0.09 & 0 & 3 & 0.40 & 7 & 0.06 \\
Dixidae & 0.01 & 0 & 1 & 0.10 & 1 & 0.01 \\
Gammaridae & 0.57 & 0 & 22 & 2.33 & 25 & 0.23 \\
Ostracoda & 0.03 & 0 & 3 & 0.29 & 1 & 0.01 \\
Pisidium spp. & 0.01 & 0 & 1 & 0.10 & 1 & 0.01 \\
Lumbricidae & 0.01 & 0 & 1 & 0.10 & 1 & 0.01 \\
Staphylinidae larvae & 0.01 & 0 & 1 & 0.10 & 1 & 0.01 \\
Terrestrial spiders & 0.02 & 0 & 1 & 0.13 & 2 & 0.02 \\
\hline
\end{tabular}

used to analyse the relationship between total length of nymphs and number of prey items in the gut contents.

To assess if individuals from both streams could be treated and analysed together, a Multidimensional Scaling analysis was performed using ingested prey items as variables (Quinn \& Keough 2002).

\section{Results}

The three biometric measures of nymphal size were highly correlated to each other (total length vs. pronotum width: Kendall Tau $=0.90$; total length vs. fore-right wing pad length: Kendall $T a u=0.85$; pronotum width vs. fore-right wing pad length: Kendall Tau $=0.91 ; p<0.05$ and $N=$ 211 in all the cases). Thus we selected total length to represent nymphal size.

From both streams, 211 individuals were studied, 82 of which were dissected and 129 were cleared.
Guts of 30 nymphs were completely empty, and 71 contained only non-animal material. A Multidimensional Scaling analysis was performed using ingested prey items as variables to detect possible groupings in individuals by stream. The Stress value obtained with this analysis was equal to $0.014(1.4 \%)$, indicating an almost perfect fit. As shown in Fig.1, individuals from both streams do not show a clear ordination or grouping, so all the individuals can be analysed together.

Non-animal material in gut contents was represented by detritus (mean \pm standard deviation of the total gut content $=80.6 \pm 31.8 \%$ ), coarse particulate organic matter $(6.4 \pm 21.7 \%)$ and hyphae $(0.17 \pm 0.78 \%)$. Twenty-four of these

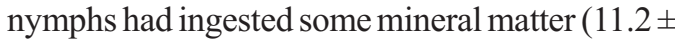
$22.8 \%$ ).

The remaining 110 nymphs contained both animal and non-animal matter, the latter probably derived from the gut of their prey. These nymphs fed mainly on Chironomidae (30 guts), Gamma- 
Table 2. Gamma correlation between total length $(\mathrm{mm})$ and number of aquatic invertebrate prey type in guts of Cordulegaster boltoni nymphs. Values marked with an asterisk are significant at $p<0.05$.

\begin{tabular}{lc}
\hline Prey item & Total length \\
\hline Ephemeroptera & $0.36^{*}$ \\
Plecoptera & 0.02 \\
Odonata & $0.77^{*}$ \\
Trichoptera & $0.44^{*}$ \\
Coleoptera & 0.58 \\
Chironomidae & $-0.52^{*}$ \\
Simuliidae & $-0.39^{*}$ \\
Diptera & 0.32 \\
Gammaridae & $0.62^{*}$ \\
Ostracoda & 0.70 \\
Pisidium spp. & 0.49 \\
Lumbricidae & 0.77 \\
\hline
\end{tabular}

ridae (25 guts), Trichoptera (10 guts), Simuliidae (7 guts), Ephemeroptera (14 guts) and Plecoptera (7 guts) (Table 1).

There was a weak positive correlation between total length and number of prey ingested (Kendall Tau=0.27; $p<0.05$ ). Size of the nymphs was positively correlated to the number of Ephemeroptera, Odonata, Trichoptera and Gammaridae in the gut content, and negatively correlated to that of Chironomidae and Simuliidae (Table 2).

\section{Discussion}

Cordulegaster boltoni is widespread in Europe, and represents one of the most typical Anisopteran dragonflies in running water systems. Our study provides the first record on the diet of a Mediterranean population of $C$. boltoni.

Larvae appeared to be opportunistic predators, taking a wide variety of prey, which were widely distributed. Aquatic insects dominated the diet of nymphs, but crustaceans, annelids and molluscs were also preyed upon. Furthermore, we found that terrestrial organisms that accidentally fall into the water can be captured and ingested by $C$. boltoni larvae. We detected an ontogenetic shift in the diet that supports previous studies (Ormerod et al. 1990). Small juvenile larvae appeared to feed particularly on small, less mobile and soft-bodied prey, such as Chironomi- dae and Simuliidae, whereas larger individuals fed on larger, mobile and hard-bodied organisms, such as Gammaridae, Ephemeroptera, Odonata, and Trichoptera. Accordingly, it is likely that as the size of the dragonfly increases, its ability to capture larger, more robust and mobile prey also improves. Inter alia, the presence of different trophic spectra in different size classes may constitute an important advantage to minimize intraspecific competition, which has been reported as an important limiting factor in low order streams (Bo \& Fenoglio 2005).

It has been observed in previous studies that Odonata larvae do not tend to actively seek for prey but rather to wait immobile and concealed in vegetation or (as is the case in Cordulegaster spp.) sediment, until a suitable food item comes within range of a forward rush and strike with the mouthparts (Askew 2004). Studies regarding trophic behaviour of this lotic species are until now scarce and conducted mostly in North Europe. For example, Jones (1950) analysed gut contents of 11 specimens of $C$. boltoni in the river Rheidol (Wales) and reported that Trichoptera larvae (Limnephilidae), Ephemeroptera nymphs (Siphlonuridae, Baetidae), and Coleoptera (a large larva and one adult of Dytiscidae) were included in the diet. Moreover, a study in Upland Wales pointed out that the diet of C. boltoni included Oligochaeta, Plecoptera (Leuctridae and Perlodidae) and Ephemeroptera (Baetidae and Leptophlebiidae) nymphs, and Trichoptera (Rhyacophilidae, Polycentropodidae and Limnephilidae) and Diptera (Simuliidae, Chironomidae and Tipulidae) larvae (Ormerod et al. 1990). These authors also observed that larger larvae ate a wider variety of prey types than smaller larvae, as reported in our study. Moreover, they recorded that small individuals of Cordulegaster fed mostly on small chironomids, while larger specimens fed more frequently on simuliids, stonefly nymphs and polycentropodid caddisflies. In a more recent study, Woodward and Hildrew (2002) examined the impact of $C$. boltoni as a new top predator having recently invaded Broadstone Stream (England). Field enclosure/exclosure experiments were conducted to assess the impact of the invader on the benthic community. Depletion of prey varied seasonally and among taxa, and was highest when prey densities and en- 
counter rates were high. The authors observed that mobile prey were most strongly captured and that depletion of prey was due solely to consumption (predators did not induce emigration as previously hypothesized for other top predators with stalking behaviour, such as large-sized Systellognatha stoneflies).

Our study suggests that $C$. boltoni is not exclusively an ambush predator, but it can explore actively the river bottom to capture a wide range of prey. This large-sized dragonfly can be considered one of the most representative carnivorous insects in lowland small order streams (which, because of their environmental characteristics, are often devoid of fish and stoneflies), where it acts as the top predator in the benthic trophic food webs.

Acknowledgments. We thank F. Ravetti and other Rangers of the Rocchetta Tanaro Natural Park, and M. Pessino for help during field activity. J. Suhonen and an anonymous reviewer are also thanked for their constructive comments on an earlier version of the manuscript. This study was supported by Ente Parchi Astigiani grants.

\section{References}

Askew, R. R. 2004: The dragonflies of Europe. Second Edition. - Harley Books, Colchester. 308 pp.

Bello, C. L. \& Cabrera, M. I. 1999: Uso de la técnica microhistológica de Cavender y Hansen en la identificación de insectos acuáticos. - Boletín Entomológico Venezolano 14: 77-79. [In Italian.]

Bergelson, J. M. 1985: A mechanistic interpretation of prey selection by Anax junius larvae (Odonata: Aeschnidae). - Ecology 66: 1699-1705.

Blois, C. 1985: Diets and resource partitioning between larvae of three anisopteran species. - Hydrobiologia 126: 1573-5117.

Blois, C. 1990: Influence of prey densities on prey selection in Anax imperator larvae (Odonata: Aeshnidae). - Aquatic Insects 12: 209-217.

Blois, C. 2006: The larval diet of three anisopteran (Odonata) species. - Freshwater Biology 15: 505-514.

Blois, C. \& Cloarec, A. 1985: Influence of experience on prey selection by Anax imperator larvae (AeschnidaeOdonata). - Zeitschrift für Tierpsychologie 68: 303312.

Bo, T. \& Fenoglio, S. 2005: Age-related shift in the diet of Perla marginata in a woodland Apenniic creek of NW Italy (Plecoptera: Perlidae). — Entomologia Generalis 28: 147-154.

Bo, T., Fenoglio, S., López-Rodríguez, M. J., Tierno de Figueroa, J. M. 2008: Trophic behavior of two Perlidae species (Insecta, Plecoptera) in a river in Southern
Spain. - International Review of Hydrobiology 93: 167-174.

Bo, T., Fenoglio, S. \& Ravetti, F. 2010: Manuale per il riconoscimento dei principali gruppi di macroinvertebrati bentonici fluviali nei Parchi e nelle Riserve naturali astigiane. — NuovaStampa Ed. Revello. 128 pp. [In Italian.]

Cammarata, M., Fenoglio, S., López-Rodríguez, M. J., Bo, T. \& Tierno de Figueroa, J. M. 2007: Prey selection of Perla grandis (Rambur, 1841) nymphs (Plecoptera, Perlidae) in Borbera Stream (NW Italy). — Boletín de la Sociedad Entomológica Aragonesa 41: 271-274.

Corbet, P. S. 1962: A biology of dragonflies. - Witherby. London. 247 pp.

Corbet, P. S., Longfield, C. \& Moore, N. W. 1960: Dragonflies. - Collins, London. 260 pp.

Donath, H. 1987: Untersuchungen in einer Larvenkolonie von Cordulegaster boltoni (Donovan) in der Niederlausitz. — Libellula 6: 105-116.

Fenoglio, S., Bo, T., Tierno de Figueroa, J. M. \& Cucco, M. 2008: Nymphal growth, life cycle and feeding habits of Potamanthus luteus (Linnaeus, 1767) (Insecta, Ephemeroptera) in the Bormida River (NW Italy). - Zoological Studies 47: 185-190.

Ferreras-Romero, M. \& Corbet, P. S. 1999: The life cycle of Cordulegaster boltoni (Donovan, 1807) (Odonata: Cordulegastridae) in the Sierra Morena Mountains (southern Spain). - Hydrobiologia 405: 39-48.

Ghetti, P. F. 1997: Manuale di applicazione dell'Indice Biotico Esteso. - Provincia Autonoma di Trento. Trento. 222 pp. [In Italian.]

Johnson, D. M. 1991: Behavioral ecology of larval dragonflies and damselflies. - Tree 6: 8-13.

Jones, J. R. E. 1950: A further ecological study of the river Rheidol: the food of the common insect of the mainstream. - The Journal of Animal Ecology 19: 159174.

Kiauta, B. 1964: Beobachtungen betreffs der Biologie, der Ökologie und der Ethologie der Quelljungfern im Bergland von Skofja Loka (Odonata-Cordulegasteridae). - Loski Razgledi 11: 183-192.

Lohmann, H. 1992: Revision der Cordulegastridae. 1. Entwurf einer neuen Klassifizierung der Familie (Odonata: Anisoptera). - Opuscula Zoologica Fluminensia 96: 1-18.

Lohmann, H. 1993: Revision der Cordulegastridae. 2. Beschreibung neuer Arten in den Gattungen Cordulegaster, Anotogaster, Neallogaster und Sonjagaster (Anisoptera). — Odonatologica 22: 273-294.

Lombardo, P. 1997: Predation by Enallagma nymphs (Odonata, Zygoptera) under different conditions of spatial heterogeneity. - Hydrobiologia 356: 1-9.

López-Rodríguez, M. J., Tierno de Figueroa, J. M., Fenoglio, S., Bo, T. \& Alba-Tercedor, J. 2009: Life strategies of 3 Perlodidae species (Plecoptera) in a Mediterranean seasonal stream in southern Europe. - Journal of the North American Benthological Society 28: 611625.

Monakov, A. V. 2003: Feeding of freshwater invertebrates. - Kenobi Productions, Ghent. 400 pp. 
Ormerod, S. J., Weatherley, N. S. \& Merrett, W. J. 1990: The influence of conifer plantations on the distribution of the Golden Ringed Dragonfly Cordulegaster boltoni (Odonata) in Upland Wales. - Biological Conservation 53: 241-251.

Quinn, G. \& Keough, M. 2002: Experimental design and data analysis for biologists. - Cambridge University Press, Cambridge. 537 pp.

Rebora, M., Piersanti, S. \& Gaino, E. 2004: Visual and mechanical cues used for prey detection by the larva of Libellula depressa (Odonata Libellulidae). - Ethology Ecology \& Evolution 16: 133-144.

Schütte, C. 1997: Egg development and early instars in Cordulegaster boltoni immaculifrons Selys: a field study (Anisoptera: Cordulegastridae). — Odonatologica 26: 83-87.
Siegel, S. \& Castellan, N. J. 1988: Nonparametric statistics for the behavioral sciences. - McGraw-Hill, New York. 399 pp.

StatSoft Inc. 2008: STATISTICA (data analysis software system), version 8.0. - [www document] URL http:// www.statsoft.com/.

Stewart, K. W. \& Stark, B. P. 2002: Nymphs of North American Stonefly genera (Plecoptera). — The Caddis Press. Columbus. 510 pp.

Tierno de Figueroa, J. M., Sezzi, E. \& Fochetti, R. 2003: Feeding in the genus Tyrrhenoleuctra (Plecoptera Leuctridae). - Bollettino della Società Entomologica Italiana 134: 207-210.

Woodward, G. \& Hildrew, A. G. 2002: The impact of a sitand-wait predator: separating consumption and prey emigration. - Oikos 99: 409-418. 